\title{
Microstructural Evolution and Sintering of Suspension Plasma- Sprayed Columnar Thermal Barrier Coatings
}

\author{
Omkar Aranke ${ }^{1}$ Mohit Gupta ${ }^{1}$ Nicolaie Markocsan ${ }^{1} \cdot$ Xin-Hai $\mathbf{L i}^{2}$ • \\ Björn Kjellman ${ }^{3}$
}

Submitted: 25 June 2018/in revised form: 4 October 2018/Published online: 25 October 2018

(C) The Author(s) 2018

\begin{abstract}
Suspension plasma spray (SPS) is capable of producing coatings with porous columnar structure, and it is also a much cheaper process compared to the conventionally used electron beam physical vapor deposition (EBPVD). Although TBCs with a columnar microstructure that are fabricated using SPS have typically lower thermal conductivity than EB-PVD, they are used sparingly in the aerospace industry due to their lower fracture toughness and limited lifetime expectancy. Lifetime of TBCs is highly influenced by the topcoat microstructure. The objective of this work was to study the TBCs produced using axial SPS with different process parameters. Influence of the microstructure on lifetime of the coatings was of particular interest, and it was determined by thermal cyclic fatigue testing. The effect of sintering on microstructure of the coatings exposed to high temperatures was also investigated. Porosity measurements were taken using image analysis technique, and thermal conductivity of the coatings was determined by laser flash analysis. The results show that axial SPS is a promising method of producing TBCs having various microstructures with good lifetime. Changes in microstructure of topcoat due to sintering were seen evidently in porous coatings,
\end{abstract}

This article is an invited paper selected from presentations at the 2018 International Thermal Spray Conference, held May 7-10, 2018, in Orlando, Florida, USA, and has been expanded from the original presentation.

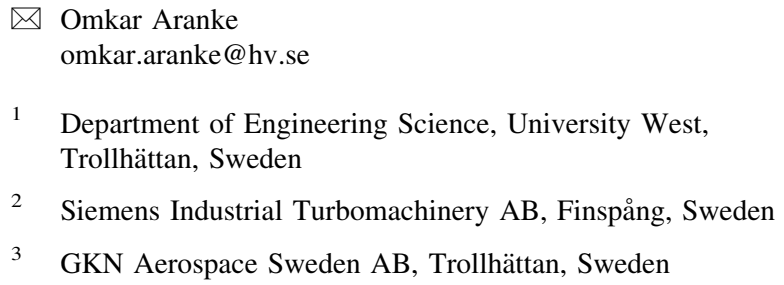

whereas dense topcoats showed good resistance against sintering.

Keywords columnar microstructure $\cdot$ sintering . suspension plasma spray · thermal barrier coating · thermal conductivity $\cdot$ thermal cyclic test

\section{Introduction}

Thermal barrier coatings (TBCs) are used to protect the metallic components which are used in the hot sectors of the gas turbines. TBCs having better functional performance will allow higher operating temperatures resulting in complete fuel combustion in the gas turbine engines delivering higher efficiency along with lower emissions (Ref 1-3). The development of TBCs fabricated by suspension plasma spray (SPS) is of high commercial interest as SPS is capable of producing coatings with strain-tolerant columnar microstructure similar to the conventional electron beam physical vapor deposition (EB-PVD) process (Ref 4, 5). It is also well known that TBCs produced using SPS can have lower thermal conductivity than other conventional processes due to a highly porous microstructure (Ref 6-8). Moreover, SPS is a comparatively cheaper technique than EB-PVD, in terms of both initial investment and running costs (Ref 5). Lower costs with SPS imply that SPS can not only be used as a replacement of EB-PVD but it could also be used for a variety of components in gas turbines including components where less strain-tolerant APS coatings were employed earlier due to lower costs, and more importantly, the existing infrastructure for APS can be utilized making it a potentially widely available technology. 
Due to the use of submicron and nanometric size of powder particles (Ref 9), suspension spraying is capable of producing coatings with a large range of porosity, and columnar structure (Ref 9-12). Characteristic microstructures mentioned in the literature are: feathery type, densely packed columnar, vertically cracked and highly porous (Ref 7, 13). Even though SPS TBCs exhibit many of the above-mentioned desirable characteristics, they still have issues with respect to their durability and lifetime performance of the coatings (Ref 14, 15).

Lifetime of TBCs is mainly governed by the topcoat microstructure, fabrication technique and also the topcoatbond coat interface roughness (Ref 16, 17). Several failure mechanisms of TBCs have been reported previously (Ref 14, 18, 19), among which cracking at the top coat-bond coat interface due to induction of thermo-mechanical stresses is the most common one. These stresses are induced during thermal cyclic testing because of mismatch in coefficient of thermal expansion (CTE) of different layers in the TBC system. In this case of longer thermal exposure at high temperatures, the crack propagation is further assisted by the growth of thermal grown oxide (TGO) that grows on the top of the bond coat. Curry et al. (Ref 6) compared dense vertically cracked APS TBCs with vertically cracked and columnar SPS TBCs and found that columnar TBCs resulted in lower thermal conductivity and significant improvements in thermal cyclic fatigue (TCF) lifetime. Ganvir et al. (Ref 20) compared different columnar microstructures created by varying spray parameters and found that TBC lifetime significantly increased with increasing fracture toughness of the topcoat layer. They also found a strong correlation between topcoat porosity and TBC lifetime, with the lifetime decreasing with the increase in total porosity. Bernard et al. (Ref 21) studied the influence of topcoat microstructure on TBC lifetime and concluded that a columnar structure with wellseparated columns showed higher lifetime as compared to compact columnar structure.

The ceramic topcoat also undergoes excessive sintering during the thermal cyclic testing that leads to a reduction in strain tolerance of the coatings, which in turn leads to an increase in the stress level within the TBC system (Ref 16). It has been reported in the previous studies that in case of APS TBCs the sintering of topcoat results in closure of pores and cracks, which in turn results in reduction in total porosity of the coating (Ref 22-24). However, due to the complex microstructure of SPS TBCs having porosity ranging from micrometric to nanometric scale, it is difficult to fully understand the changes in microstructure due to sintering. It is typically observed in SPS TBCs that after long exposure at high temperatures, the inter-columnar gaps are widened, not only after thermal cycling but also after isothermal heat treatment (Ref 25,26$)$. Reduction in fine porosity due to densification of the pores present within the columns resulting in shrinkage of columns and opening up of inter-columnar gaps has also been observed (Ref 25, 26). Sintering of topcoat results in increase in thermal conductivity (Ref 26) and can result in weak intercolumnar bonding due to shrinkage of the columns and thus provide easier paths for oxygen ingress as well as crack propagation in the topcoat between the columns (Ref 25). The as-sprayed microstructure plays a crucial role in determining the extent of topcoat sintering which changes the functional performance of the coating (Ref 26-28). Therefore, in order to increase the durability and improve the lifetime and sintering resistance of the coatings, it is essential to have a better understanding of the relationships between spray parameters, microstructure and failure mechanisms.

The aim of this work was to study the effect of various combinations of processing conditions of SPS TBCs on their microstructure, thermal conductivity, sintering resistance and lifetime. The topcoat microstructure was varied while keeping the same bond coat chemistry in all the coatings. Thermal conductivity of the coatings was calculated from thermal diffusivity data measured using laser flash analysis (LFA). Thermal cyclic fatigue (TCF) testing was used to determine the lifetime of the samples as well as to study the changes in topcoat microstructure.

\section{Experimental Methods}

\section{Sample Preparation}

In this study, seven types of SPS TBCs were investigated. The spray parameters used for spraying the topcoats are presented in Table 1. The Mettech Axial III high-power plasma gun equipped with NanoFeed 350 suspension feeder (Northwest Mettech Corp., Canada) was used to spray 8 wt.\% yttria partially stabilized zirconia (YSZ) suspension with $25 \%$ solid load in ethanol and $D_{50}=0.3-1.0 \mu \mathrm{m}$ (Metco 6608, Oerlikon Metco) for all the samples. The target thickness of the topcoat was kept as $500 \mu \mathrm{m}$ for all the samples. The plasma gas used was a mixture of $\mathrm{Ar}, \mathrm{H}_{2}$ and $\mathrm{N}_{2}$ with a constant total gas flow of $300 \mathrm{~L} / \mathrm{min}$.

The aim behind selecting the parameters given in Table 1 was to vary the microstructure of the coatings from porous and feathery columnar to densely packed structure. In the sample R7, a bilayer topcoat was sprayed having thickness of 150 and $350 \mu \mathrm{m}$ for the first denser layer and second columnar layer, respectively. The denser layer can provide good fracture toughness that provides better resistance against crack propagation near the topcoat-bond coat interface, while the columnar layer with porous microstructure can provide lower thermal conductivity and 
Table 1 Spray parameters used to produce the topcoats

\begin{tabular}{|c|c|c|c|c|}
\hline Sample ID & Spray distance, $\mathrm{mm}$ & Surface speed, $\mathrm{m} / \mathrm{min}$ & Feed rate, $\mathrm{ml} / \mathrm{min}$ & Power, kW \\
\hline R1 & 100 & 100 & 100 & 138 \\
\hline $\mathrm{R} 2$ & 100 & 100 & 45 & 138 \\
\hline R3 & 75 & 75 & 100 & 138 \\
\hline $\mathrm{R} 4$ & 75 & 75 & 45 & 122 \\
\hline $\mathrm{R} 5$ & 75 & 75 & 45 & 138 \\
\hline R6 & 75 & 75 & 45 & 149 \\
\hline \multicolumn{5}{|l|}{ R7 } \\
\hline 1st layer & 75 & 75 & 45 & 149 \\
\hline 2nd layer & 100 & 100 & 100 & 138 \\
\hline
\end{tabular}

higher strain tolerance that is essential for increasing the lifetime of TBCs (Ref 29).

Prior to spraying the topcoats, Hastelloy $\mathrm{X}$ substrates were first grit-blasted and then sprayed with a metallic bond coat using a NiCoCrAlY powder (AMDRY 386, Oerlikon Metco) by a HVAF equipment using the M3 supersonic HVAF spray gun (Uniquecoat Technologies, USA). The thickness of the bond coat for all the samples was kept the same with a target thickness of $200 \mu \mathrm{m}$. Substrates in dimensions $25.4 \mathrm{~mm}$ diameter $\times 6 \mathrm{~mm}$ thickness were used for microstructural evaluation, TCF testing and high-temperature sintering study, while for evaluation of thermal conductivity, substrates in dimensions $25 \mathrm{~mm} \times 25 \mathrm{~mm} \times 1.6 \mathrm{~mm}$ were used.

\section{Microstructure Characterization}

For the metallography analysis, the samples were first coldmounted in a low-viscosity epoxy resin using vacuum impregnation technique, then sectioned using a cutting disk and then cold-mounted again in high-viscosity epoxy resin for grinding and polishing. The polishing was performed using a semiautomatic Buehler AutoMet 300 Pro (Buehler, Lake Bluff, IL, USA) polishing machine. Microstructures of the as-sprayed coatings and the failed samples after lifetime testing were studied using a Hitachi TM3000 tabletop scanning electron microscope (SEM) (HITACHI, Tokyo, Japan). Gold sputtering was carried out on the polished samples to reduce the charging effect.

The coating thickness and column density were measured on 10 SEM micrographs taken at $100 \times$ magnification across the coating cross section. For column density measurements, a line of fixed length was drawn at the center of the topcoat layer in the micrographs using Microsoft Paint software. All vertical cracks (intercolumnar spacing) intercepting this line were counted. The column density was then calculated using following Eq 1:
Column density (cracks/mm)

$=$ No. of vertical cracks

intercepting the line/true length of the line

An average of 10 measurements was then taken to determine the final column density.

The topcoat surface roughness was measured using a stylus-based surface profilometer, Surftest SJ-301 (Mitutoyo Europe GmbH, Germany). An average of 10 recordings per sample was taken to calculate the roughness of the coating.

\section{Porosity Analysis}

Measuring porosity in SPS coatings is quite challenging since it contains porosity at different scales starting from micrometric columnar gaps to sub-micrometric and nanoscale pores. Therefore, in order to get an overall estimate of all these types of pores, SEM micrographs at different magnification levels were captured and analyzed using image analysis (IA) technique. To measure the porosity at micrometric scales consisting of columnar gaps and big cracks, micrographs at a magnification of $500 \times$ were taken, while for the sub-micrometric and nanoscale pores, micrographs at a magnification of $5000 \times$ were taken. A total of 10 SEM micrographs were captured for both low and high magnification across the cross section of the coating to determine the relative porosity values among different coatings. The micrographs were first converted into binary images using appropriate algorithm in a public domain free software, ImageJ (Ref 30). A count mask was applied on these binary images with pixel area of less than $2 \mu \mathrm{m}^{2}$ to calculate fine-scale porosity on $5000 \times$ images and $2 \mu \mathrm{m}^{2}$ to infinity to calculate coarse porosity on $500 \times$ images (Ref 13).

The apparent density of the coatings was obtained using following Eq 2:

$$
\rho a=\rho b(1-P)
$$


here $\rho a$ is the apparent coating density $\left(\mathrm{g} / \mathrm{cm}^{3}\right), \rho b$ is the bulk density of YSZ $\left(6.1 \mathrm{~g} / \mathrm{cm}^{3}\right)$ (Ref 31$)$ and $P$ is the porosity content of the coating (area fraction).

\section{Thermal Conductivity Evaluation}

Thermal diffusivity measurements were taken at room temperature using NETZSCH 427 laser flash analysis (LFA) equipment (Netzsch Gerätebau GmbH, Germany). Samples of $10 \mathrm{~mm}$ diameter were cut using water jet cutting and were coated with a thin graphite layer to prevent direct transmission of infrared light pulse and provide better absorption (Ref 31). A three-layer Cowan model (substrate + bond coat + topcoat) was used to determine the thermal diffusivity. Specific density and thermal diffusivity measured for Hastelloy X was $0.469 \mathrm{~J} / \mathrm{g} \mathrm{K}$ and $2.889 \mathrm{~mm}^{2} / \mathrm{s}$, respectively, whereas for the bond coat, the values were $0.453 \mathrm{~J} / \mathrm{g} \mathrm{K}$ and $3.283 \mathrm{~mm}^{2} / \mathrm{s}$, respectively. The detailed procedure of thermal diffusivity and conductivity measurement can be found in the previous literature (Ref 32). Thermal conductivity was then calculated using following Eq 3:

$\lambda=\alpha \cdot C p \cdot \rho$

here is the thermal conductivity $(\mathrm{W} /(\mathrm{m} \mathrm{K})), \alpha$ is the thermal diffusivity measured using LFA technique $\left(\mathrm{mm}^{2} / \mathrm{s}\right), C p$ is the specific heat capacity which was measured previously ( $\mathrm{J} / \mathrm{g} \mathrm{K})$ and $\rho$ is the coating density measured using Eq 2.

\section{Thermal Cyclic Fatigue Testing and Heat Treatment}

Thermal cyclic fatigue (TCF) testing was performed to assess the lifetime of the coatings under long exposure at high temperatures. The samples were first heated to $1100{ }^{\circ} \mathrm{C}$ in a furnace for $1 \mathrm{~h}$ and then cooled down to $100{ }^{\circ} \mathrm{C}$ for $10 \mathrm{~min}$ using compressed air. This cycle was repeated until $20 \%$ spallation of the topcoat was visible. The failure in this case is mainly driven by the formation of a thermally grown oxide (TGO) layer due to oxidation of bond coat and the coefficient of thermal expansion (CTE) mismatch of different layers in the TBC system. Three samples from each set of coatings were tested in this study.

The same test setup was also used to study the changes in ceramic topcoat microstructure, i.e., sintering, due to thermal cyclic heat treatment. The samples were tested under the above-mentioned thermal cyclic conditions for 200 cycles and 400 cycles.

\section{Results and Discussion}

\section{Microstructure Characterization}

The microstructure images of the seven topcoats (R1-R7) produced and investigated in this study are shown in Fig. 1. It can be clearly seen that the microstructure of the coatings changes from feathery columnar to densely packed columnar structure [Fig. 1a, b, c, d, e, f and g] as spray parameters change. The topcoat of R1 [Fig. 1a] exhibited a typical feathery columnar structure with large intercolumnar gaps (indicated by arrows) having column density of around $18 \mathrm{cracks} / \mathrm{mm}$ (Table 2). The inter-columnar gaps go throughout the coating thickness. Coating R2, shown in Fig. 1(b), exhibited a feathery columnar structure, but the inter-columnar gaps were much smaller with intermediate column density (Table 2 ). This may be the consequence of employing a lower suspension feed rate that could give higher heating of the particles.

Coating R3 exhibited another commonly seen columnar structure in SPS coatings with inter-pass porosity bands, indicated by ovals in Fig. 1(c) (Ref 10). The use of higher feed rate in this case means more particles (material) were heated in the periphery of the plasma plume, which may lead to inadequate melting and formation of inter-pass porosity. The topcoat R4, shown in Fig. 1(d), also exhibited a columnar structure with a denser coating. This might be due to the use of lower feed rate and stand-off distance, resulting in better melting of particles with a higher deposition rate. The coating has more distinct vertical cracks (indicated by arrows) running all the way through the thickness of the topcoat.

Cross-section image of coatings R5 and R6, shown in Fig. 1(e) and (f), respectively, exhibited a densely packed columnar structure with some horizontal cracks starting from the column gaps. These horizontal cracks, called also branching cracks, are typical for dense TBCs and are a consequence of the high energy release during spraying and solidification of the molten zirconia particles (Ref 11). In these two coatings, the columns are tightly spaced compared to the rest of the coatings, which is also in correlation with column density values from Table 2 . The R6 topcoat had a denser microstructure than R5, probably due to the use of higher input energy. High number of branching cracks (indicated by dotted arrows) can be seen in which may be detrimental to the coating lifetime as they could propagate through the columns during thermal cycling (Ref 7). In coating R7, shown in Fig. 1(g), a bilayer topcoat was produced. The columns in the second layer continued to grow on top of the first layer columns. A denser first layer was produced than the second layer as intended during spraying. 

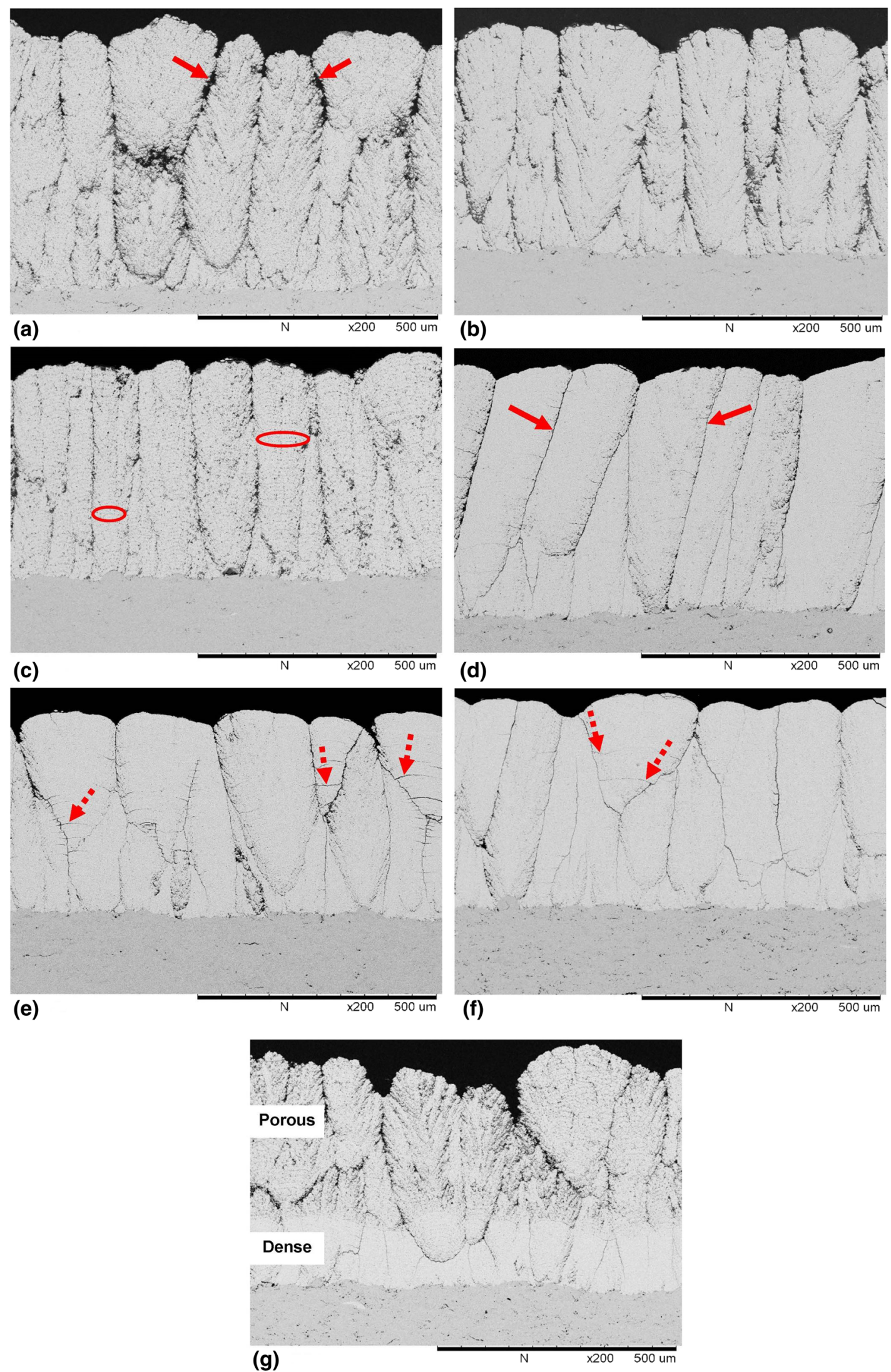

Fig. 1 Cross-section images of coating microstructures for (a) R1, (b) R2, (c) R3, (d) R4, (e) R5, (f) R6 and (g) R7 
Table 2 Column density, topcoat thickness and surface roughness for coatings R1-R7

\begin{tabular}{lccc}
\hline Sample ID & Column density, cracks/mm & Topcoat thickness, $\mu \mathrm{m}$ & Topcoat surface roughness, $\mu \mathrm{m}$ \\
\hline $\mathrm{R} 1$ & $18.4 \pm 1.14$ & $528 \pm 26$ & $15.23 \pm 1.65$ \\
$\mathrm{R} 2$ & $15.8 \pm 0.84$ & $506 \pm 22$ & $13.32 \pm 1.64$ \\
$\mathrm{R} 3$ & $13.8 \pm 0.84$ & $472 \pm 14$ & $12.15 \pm 1.07$ \\
R4 & $13.2 \pm 0.84$ & $512 \pm 19$ & $11.38 \pm 1.17$ \\
R5 & $12.6 \pm 0.55$ & $451 \pm 21$ & $9.93 \pm 0.84$ \\
R6 & $12.2 \pm 0.45$ & $449 \pm 13$ & $8.29 \pm 0.54$ \\
R7 & $12.8 \pm 0.84$ & & $14.40 \pm 1.20$ \\
\multicolumn{1}{l}{ 1st layer } & $15 \pm 1.00$ & $496 \pm 32$ & \\
2nd layer & & & \\
\hline
\end{tabular}

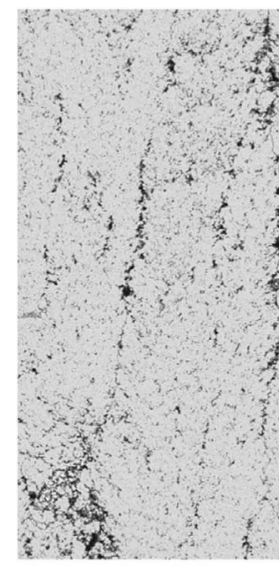

(a)

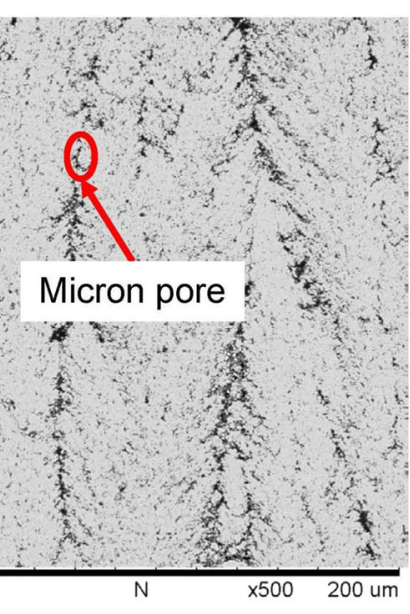

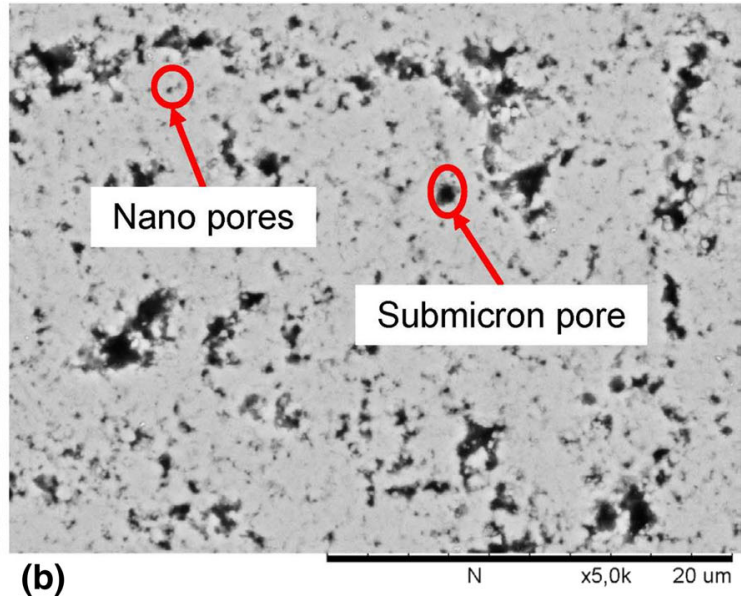

(b)

Fig. 2 SEM micrographs at two different magnifications, (a) $500 \times$ and (b) $5000 \times$ showing two different scaled porosities for coating R1 analyzed by IA technique to determine the porosity content

The topcoat surface roughness given in Table 2 is seen to be decreasing when the coating microstructure is changing from R1 to R6. These values are also going well in correlation with the column density values. A lower topcoat surface roughness is typically desired to improve combustion efficiency, indicating that coatings with dense microstructure could be beneficial to improve surface roughness.

In general, as the spray distance is reduced, more number of particles are in fully molten state during their impact and also a higher amount of thermal energy is transferred from the plasma plume to the sample. The lower feed rate also may result in more heat transferred to the in-flight particle and forming denser coatings. It can also be observed that higher the number of inter-columnar gaps or cracks, higher is the overall roughness of the topcoat.

\section{Porosity Analysis}

The porosity of different scales, present in the coatings, is highlighted in Fig. 2. The coarse porosity calculated from

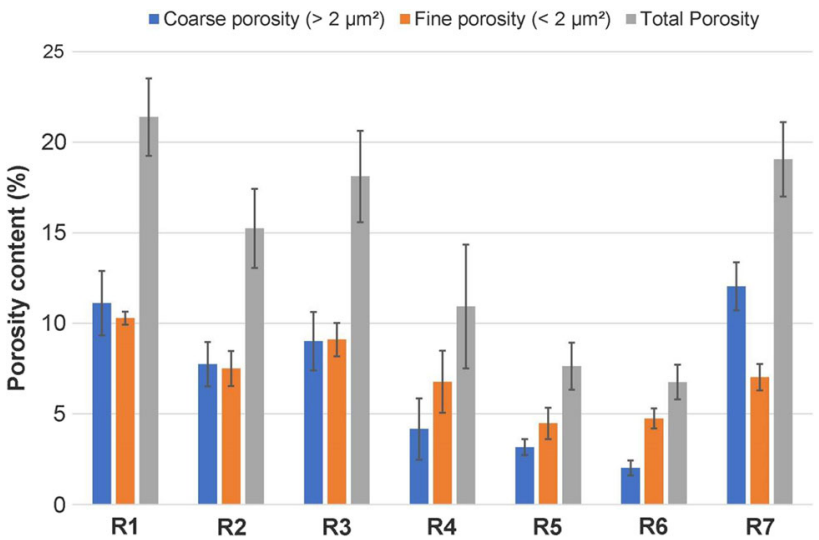

Fig. 3 Comparative distribution in area $\%$ of coarse $\left(>2 \mu \mathrm{m}^{2}\right)$, fine $\left(<2 \mu \mathrm{m}^{2}\right)$ and total porosity

$500 \times$ images is mainly attributed to the inter-columnar gaps and large pores inside the pores, while the fine porosity calculated from $5000 \times$ images is mainly attributed to the fine intra-columnar porosity.

Figure 3 summarizes the results obtained from IA for all coatings at two different magnifications $(500 \times$ and 
$5000 \times)$. Coatings R1 and R7 showed highest content of coarse porosity which can also be observed in Fig. 1(a), (b), (c), (d), (e), (f) and (g), respectively. It should be noted that measuring the porosity of a bilayer topcoat is quite challenging due to different columnar features exhibited at various scale porosities. In this study, SEM micrographs were captured from both layers at the stated magnifications to get an estimate of the porosity values of each layer. The average porosity was then calculated for the whole coating using the proportion of the thicknesses of the individual topcoat layers. Since the second topcoat layer in R7 was highly porous, the coarse porosity was dominated by the porous layer resulting in quite high value similar to $\mathrm{R} 1$, whereas due to the dense first topcoat layer, the porosity at higher magnification was quite low when compared with R1.

Coatings R2 and R3 showed almost equal coarse and fine porosity content, whereas coatings R4, R5 and R6 had higher fine porosity content than coarse porosity. This indicates that although the columns are densely packed in these three coatings, there is still a high amount of porosity at submicron and nanometric levels. SEM micrographs in Fig. 1(d), (e) and (f) also show that there are less micrometric pores and inter-columnar gaps present in these coatings as compared to other samples investigated in this study.

\section{Thermal Conductivity Evaluation}

Thermal conductivity measurement results at room temperature are shown in Fig. 4. It can be seen that coatings R1-R4 did not show much difference in thermal conductivity values, whereas coatings R5 and R6 have relatively higher thermal conductivity. These values are also well in correlation with the results obtained from porosity measurements with coatings R1-R3 showing a porous columnar microstructure and R5 and R6 showing a densely packed columnar structure ( $\operatorname{Ref} 33,34)$. The thermal conductivity

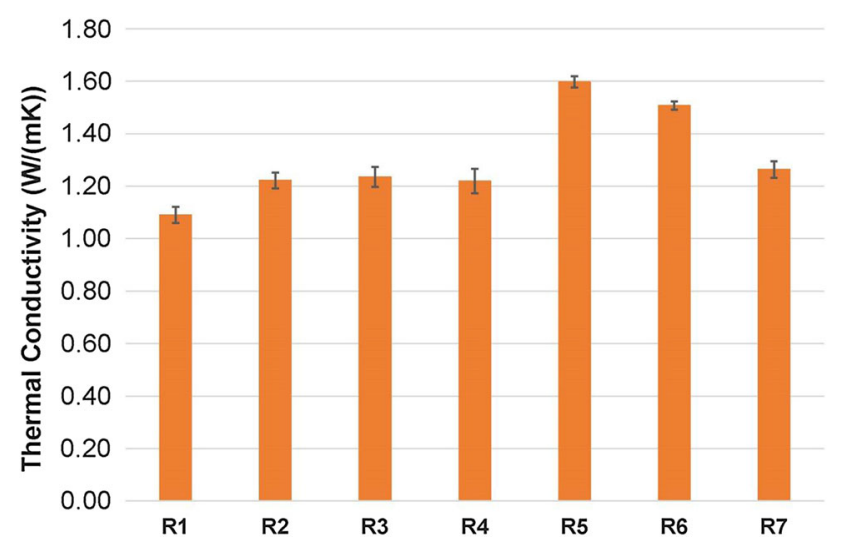

Fig. 4 Thermal conductivity values measured at room temperature of the bilayer coating R7, although higher than the porous coatings, is significantly lower than the dense coatings as expected.

As also showed in several previous studies, higher porosity in the coatings corresponds to lower thermal conductivity in SPS TBCs (Ref 7, 13). The same results are also reflected in this study with coating $\mathrm{R} 1$ showing lowest thermal conductivity and coating R5 and R6 showing the higher values. The high thermal conductivity in case of R5, R6 and R7 is attributed to the highly dense microstructure (second topcoat layer in case of R7). The SPS coatings studied in the literature were usually made porous to reduce their thermal conductivity, while in this study the objective was to produce dense coatings in order to increase their fracture toughness and potentially improve their lifetime.

\section{Thermal Cyclic Fatigue Testing}

The results from TCF testing are shown in Fig. 5. It can be seen that all the coatings showed a good lifetime with over 475 cycles and almost similar lifetime. Coating R1 had lower lifetime when compared to other porous coatings. That may be due to the high number of porous columns as discussed earlier in "Microstructure Characterization" and "Porosity Analysis" sections. These columns can shrink across their width due to sintering during thermal cycling which increases the inter-columnar gap. This widening of inter-columnar gaps may facilitate quicker propagation of cracks between the columns during thermal cycling (Ref 25).

Coating R7 had similar lifetime as that of R1 which suggests that the dense second layer in R7 had very little influence on the lifetime of the coating. The lifetime of R2 was found to be slightly higher than R1 and R7 which can be due to the feathery columnar microstructure being able to provide room for the stresses developed during thermal cycling. Coating R3 exhibiting inter-pass porosity bands

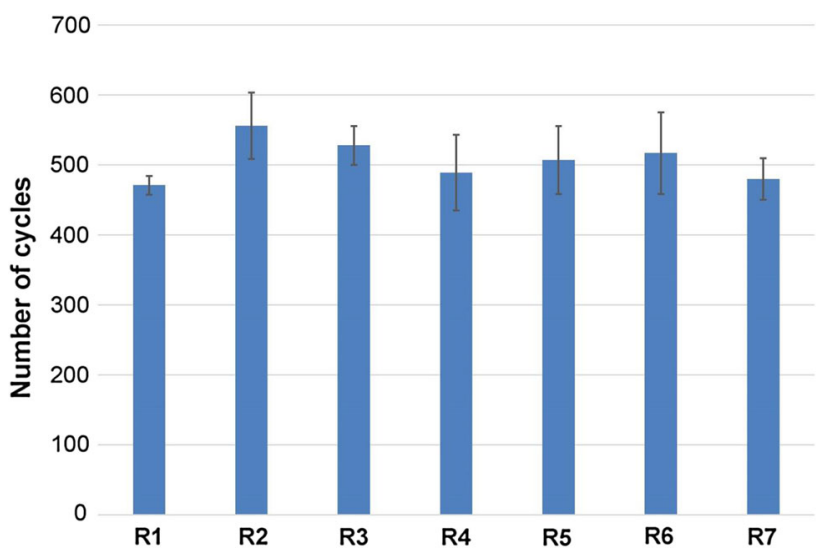

Fig. 5 Thermal cyclic fatigue lifetime result 


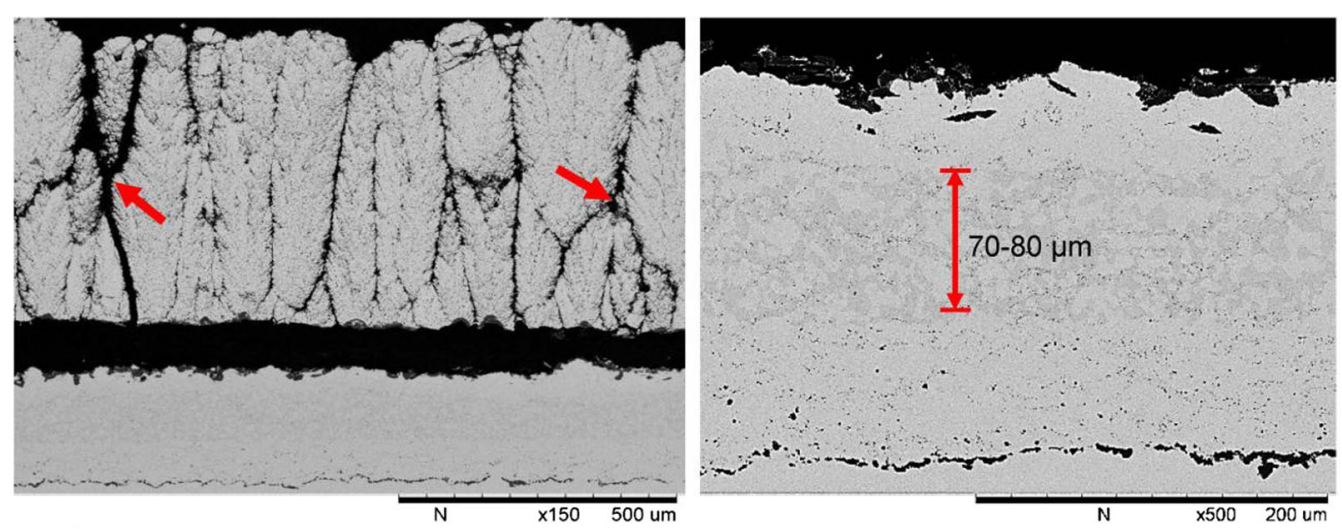

(a)
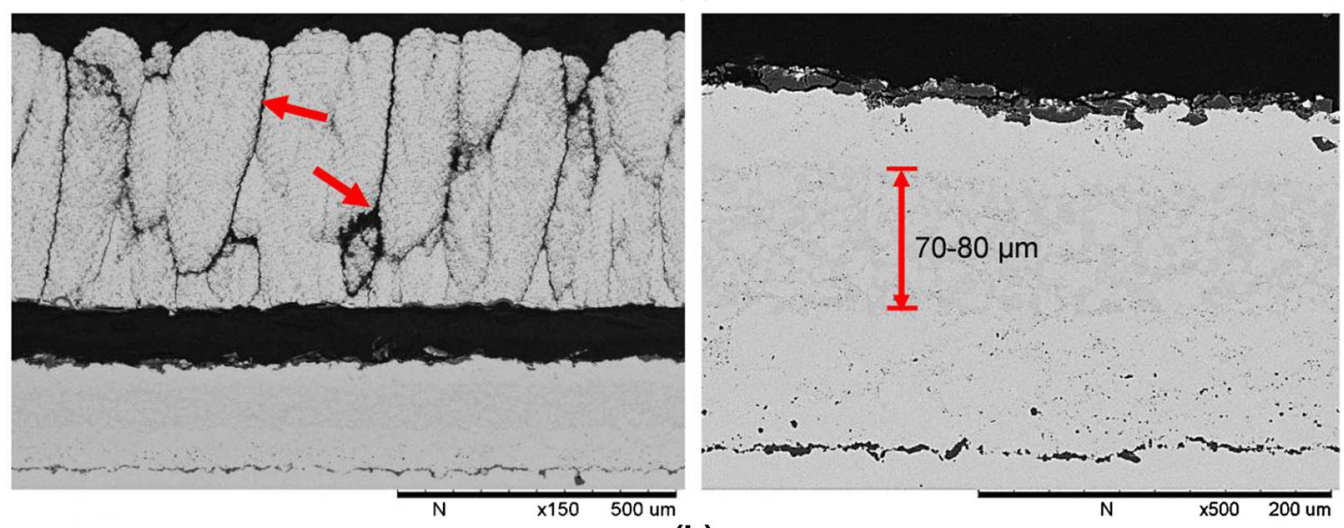

(b)
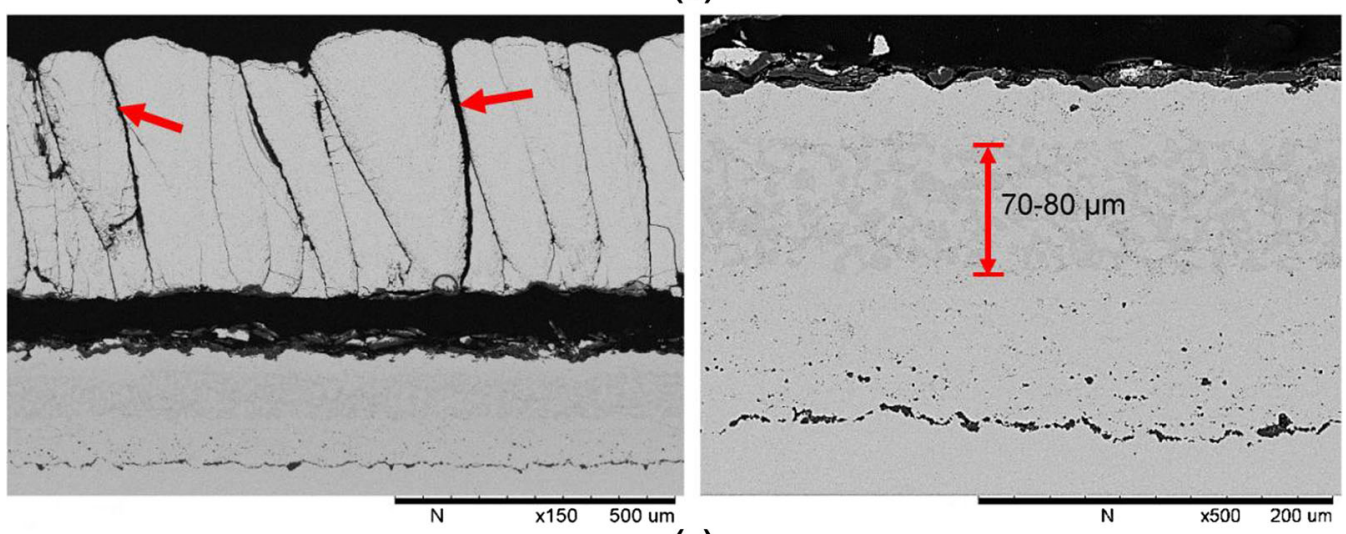

(c)
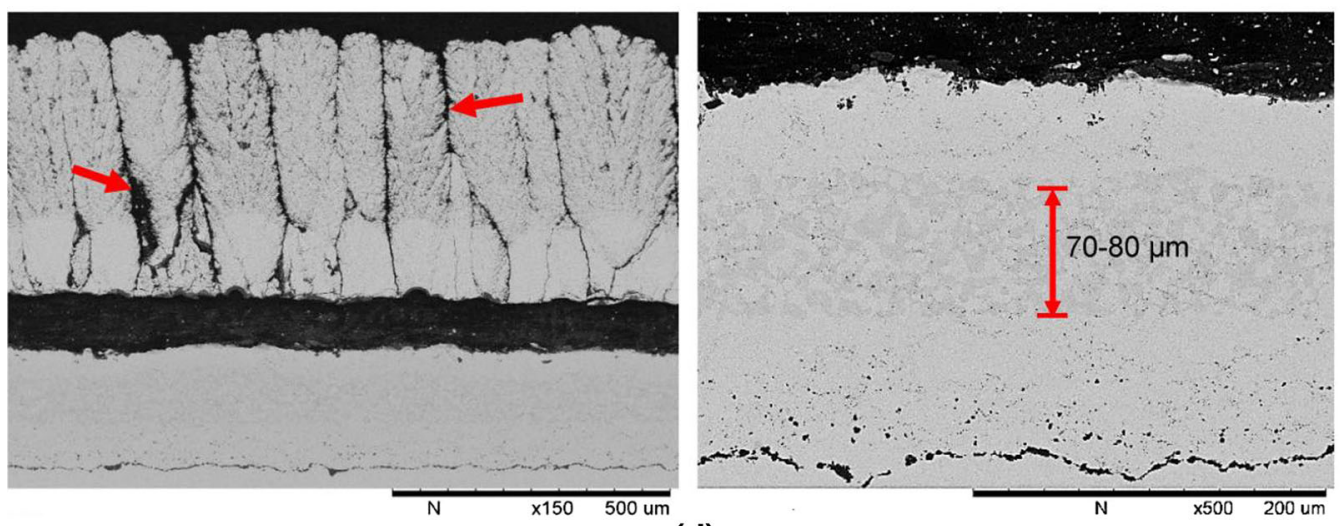

(d) 
4Fig. 6 Microstructure images of samples after failure in TCF testing (left) and thickness of remaining beta phase (right) for (a) R1, (b) R3, (c) R6 and (d) R7

also showed relatively good TCF lifetime, illustrating that porosity bands can also deal better with the stresses developed under thermal cycling. The densely packed columnar coatings R4, R5 and R6 are also seen to have nearly the same TCF lifetime. The overall results therefore suggest that the topcoat chemistry alone has less influence on the TCF lifetime.

The microstructure images of the failed samples after lifetime testing and the remaining beta phase in the bond coats for coatings R1, R3, R6 and R7 are shown in Fig. 6(a), (b), (c) and (d). It can be evidently seen from Fig. 6 that all coatings underwent considerable sintering and the failure of the coatings has occurred in the TGO layer. Similar mode of failure along with the widening or opening of the column gaps (indicated by arrows) due to sintering was observed in all the coatings. This failure mode is similar to the observations in the previous work done on assessing lifetime of SPS TBCs by thermal cycling (Ref 12, 25). The difference in expansion and contraction of topcoat and bond coat due to their CTE mismatch exerts shear forces on the TGO layer which results in the failure of coatings due to cracking within the TGO layer (Ref 25).

Figure 7(a) shows a magnified image of the cracked area within the TGO layer of the picture in Fig. 6(a) which illustrates coating R1. Same phenomenon was observed in all the other coatings. It can be clearly seen that the TGO layer is present on both sides of the topcoat-bond coat interface. The solid arrows show the alumina layer, while the dotted red arrows show the mixed oxides. The presence of alumina and mixed oxides is also confirmed by the energy-dispersive spectroscopy (EDS) analysis of the TGO layer shown in Fig. 7(b).
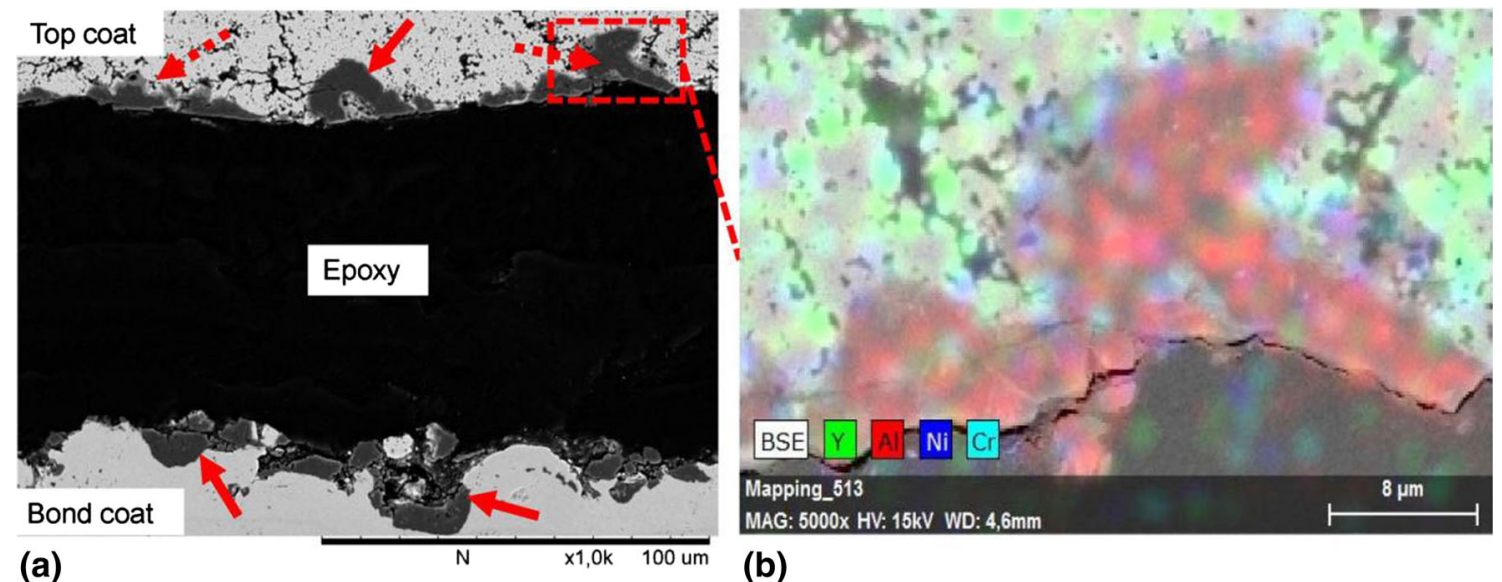

(b)
It can be noted from the microstructure image shown Fig. 6(c) that the densely packed columns have shrunk considerably across their width as stated earlier. The bilayer coating microstructure, seen in Fig. 6(d), shows that approximately $70-75 \%$ of inter-columnar gaps from the porous layer also run through the dense layer. The gaps in the porous layer are wider than in the denser layer which can be correlated with the porosity content of the coating that influences the sintering rates of the coatings. Another feature which can be seen from images shown in Fig. 6 is that the thickness of beta phase is similar for all the coatings after failure which is due to the use of same bond coat and same spray conditions and similar TCF lifetime for all the samples. Despite the relatively high number of TCF cycles, the thickness of remaining beta phase in the bond coats is still quite significant which is an indication that these coatings are capable of showing even better TCF performance.

It can be concluded from these observations that the increase in the thickness of TGO layer along with the stresses developed during thermal cycling resulted in cracking of the coating within the TGO layer which eventually led to their failure.

\section{Microstructure Changes After Thermal Cyclic Heat Treatment}

Due to prolonged exposure at high temperatures, the microstructure of TBCs changes because of continuous sintering.

The porosity measurement results for all coatings before and after heat treatment are shown in Fig. 8. YSZ TBCs produced by SPS in this study have shown an increase in porosity at coarse level and reduction in fine porosity. As it can be seen from Fig. 8, all the coatings showed a slight increase in porosity at coarse level, whereas the porosity at

Fig. 7 (a) Microstructure image of cracking within the TGO layer for coating R1 and (b) EDS mapping of TGO layer for coating R1 
fine level either decreased or remained within the standard deviation. On the other hand, the total porosity after heat treatment is same as total porosity before heat treatment. This result shows that the increase in coarse porosity after heat treatment is compensated by the decrease in fine porosity, keeping the overall porosity unchanged as

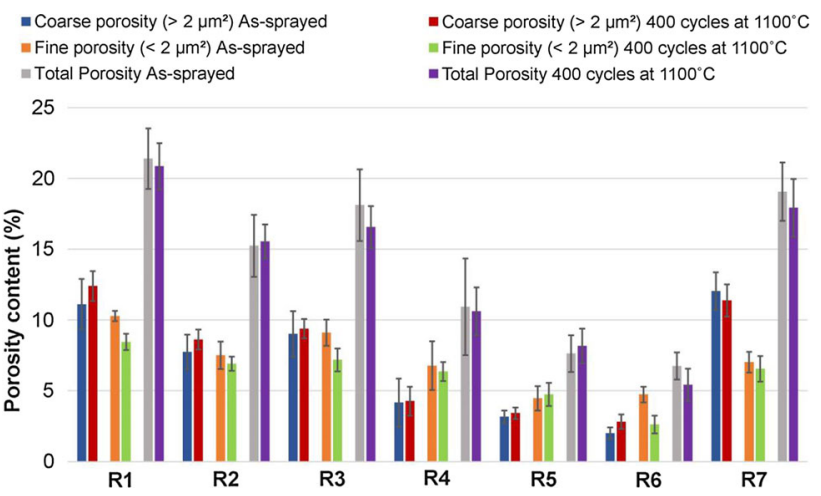

Fig. 8 Comparative distribution in area $\%$ of coarse $\left(>2 \mu \mathrm{m}^{2}\right)$, fine $\left(<2 \mu \mathrm{m}^{2}\right)$ and total porosity before and after heat treatment expected. The increase in porosity at coarse level is attributed to the widening or opening of inter-columnar gaps during thermal cycling, and such observations are also reported in the previous literature (Ref $12,26,35)$. The reduction in porosity is due to the coalescence of individual pores or densification of pores within the columns (Ref 26). A comparison between as-sprayed coatings shown in Fig. 1 and failed coatings after TCF testing shown in Fig. 6 further proves these microstructural changes. These changes can also be seen in Fig. 9 and 10 which reveal the porosity growth due to opening of inter-columnar gaps (indicated by solid arrows), and pore coalescence and densification (shown by dotted arrows) at submicron and nanometric level for coating R1 and R6, respectively.

Figure 11 and 12 shows the SEM micrographs showing the top view of the porous coating R1 and the dense coating R6, respectively, in as-sprayed condition, and after 200 cycles and 400 cycles of thermal cyclic heat treatment. It can be noticed in the micrographs at lower magnification shown in Fig. 9 that there is opening up of cracks or widening of inter-columnar gaps (indicated by circles)
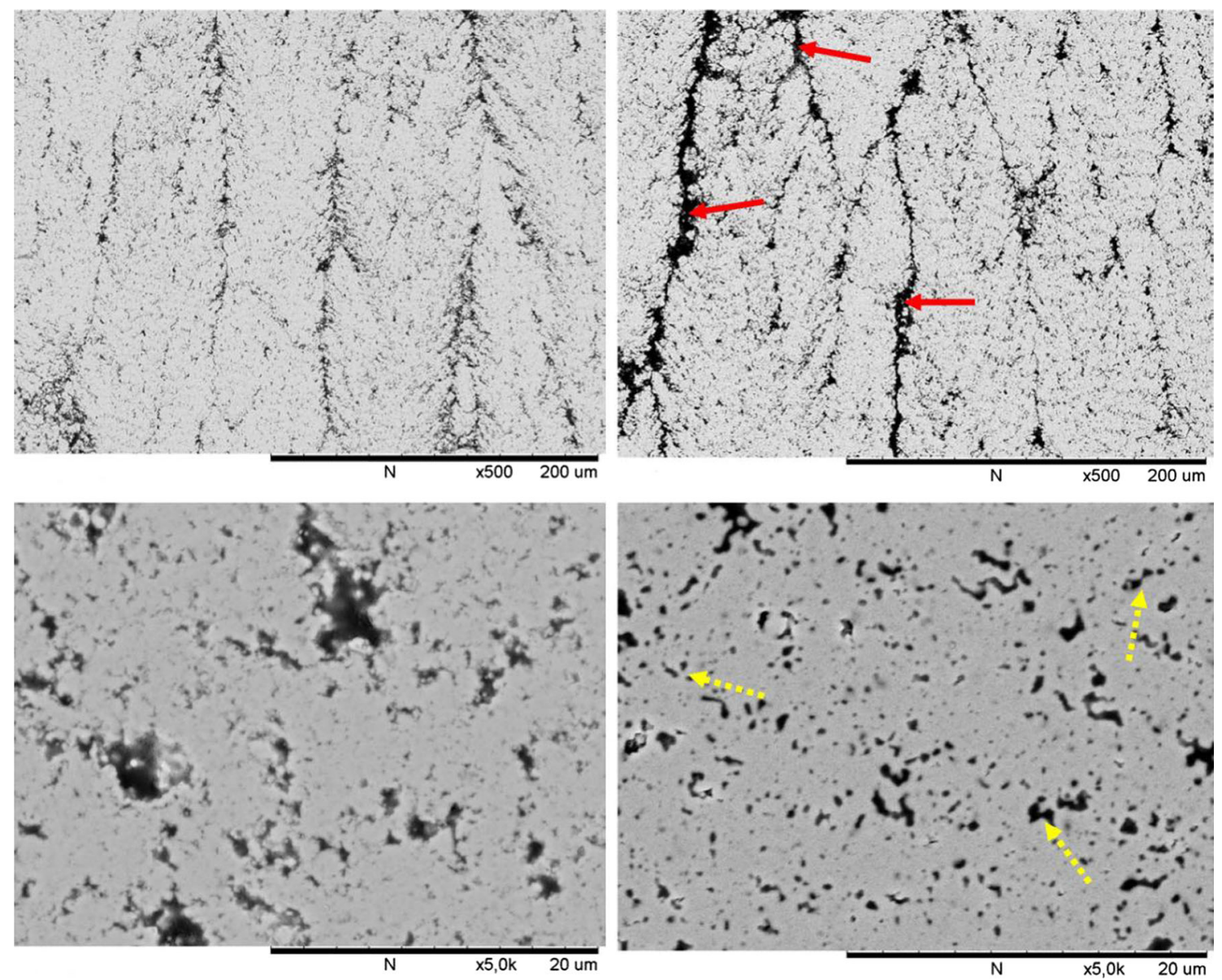

Fig. 9 SEM micrographs showing the cross section of coating R1 in as-sprayed condition (left) and after 400 cycles (right) of cyclic heat treatment at $1100{ }^{\circ} \mathrm{C}$. The top row shows the images at low magnification, while the bottom row shows the images at high magnification 

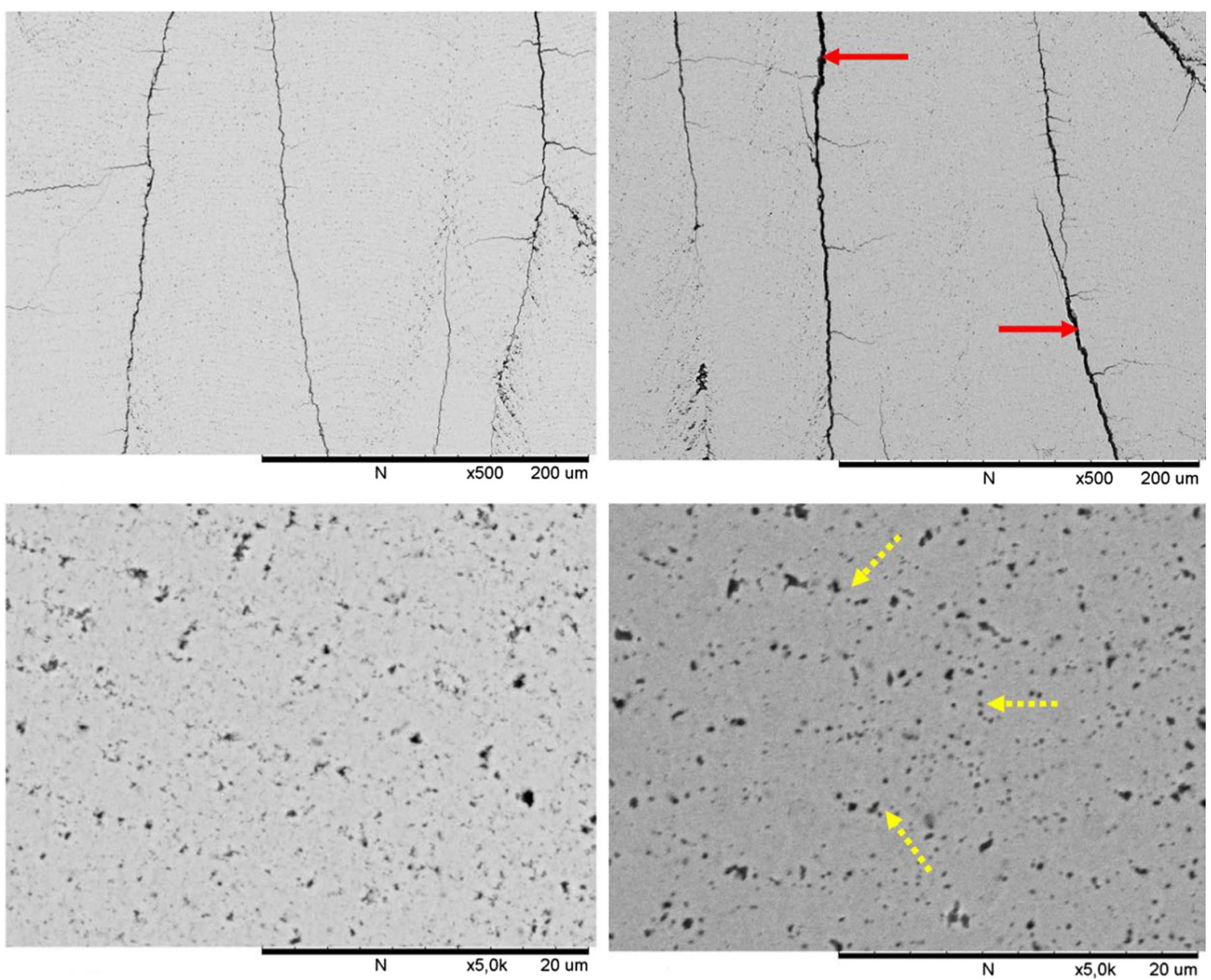

Fig. 10 SEM micrographs showing the cross section of coating R6 in as-sprayed condition (left) and after 400 cycles (right) of cyclic heat treatment at $1100{ }^{\circ} \mathrm{C}$. The top row shows the images at low magnification, while the bottom row shows the images at high magnification

along with some intra-columnar cracking (indicated by solid arrows) due to the heat treatment. When comparing the micrographs at higher magnification, it can be seen that the spherical shaped particles clearly present in as-sprayed state have started to fuse together or agglomerate (indicated by dotted arrows). These particles seem to have clustered by fusing among themselves which most probably is due to the effect of sintering at high temperatures as also observed in the previous work (Ref 25).

In case of dense coating microstructure, shown in Fig. 12, excessive cracking of the topcoat (indicated by solid arrows) after heat treatment can be seen from the micrographs at lower magnification. There is no evident widening of inter-columnar gaps as seen in the porous topcoat of R1. This observation is also reflected by the percentage of coarse porosity after heat treatment (Fig. 8) remaining the same as before heat treatment. This could be due to better fusion of the densely packed columns in the as-sprayed state making intra-columnar cracking necessary to release thermo-mechanical stresses generated due to sintering and thermal cycling. At higher magnifications, very few particles can be seen to form links among themselves and fusing together after heat treatment, which indicates that the coating may have high sintering resistance (Ref 26). Another reason for this phenomenon could be due to the presence of fewer spherical particles in the assprayed state as compared to the porous coating R1.

In general, it can be said that there are significant changes occurring in the topcoat microstructure as seen from Fig. 11 and 12 because of high-temperature sintering. The increase in porosity at coarse level after heat treatment for porous topcoats (R1, R2, R3 and R7) is slightly more than the increase in coarse porosity for dense coatings (R4, R5 and R6) which is mainly due to the excessive opening up of inter-columnar spaces. The branching cracks present in the as-sprayed microstructure could have also propagated through the inter-pass porosity bands and merged at the center of columns. Such merging of horizontal cracks due to sintering has also been reported in the literature for SPS TBCs (Ref 36). On the other hand, the decrease in percentage of fine porosity can be attributed to the coalescence of pores or fusing of spherical shaped particles due to sintering. 

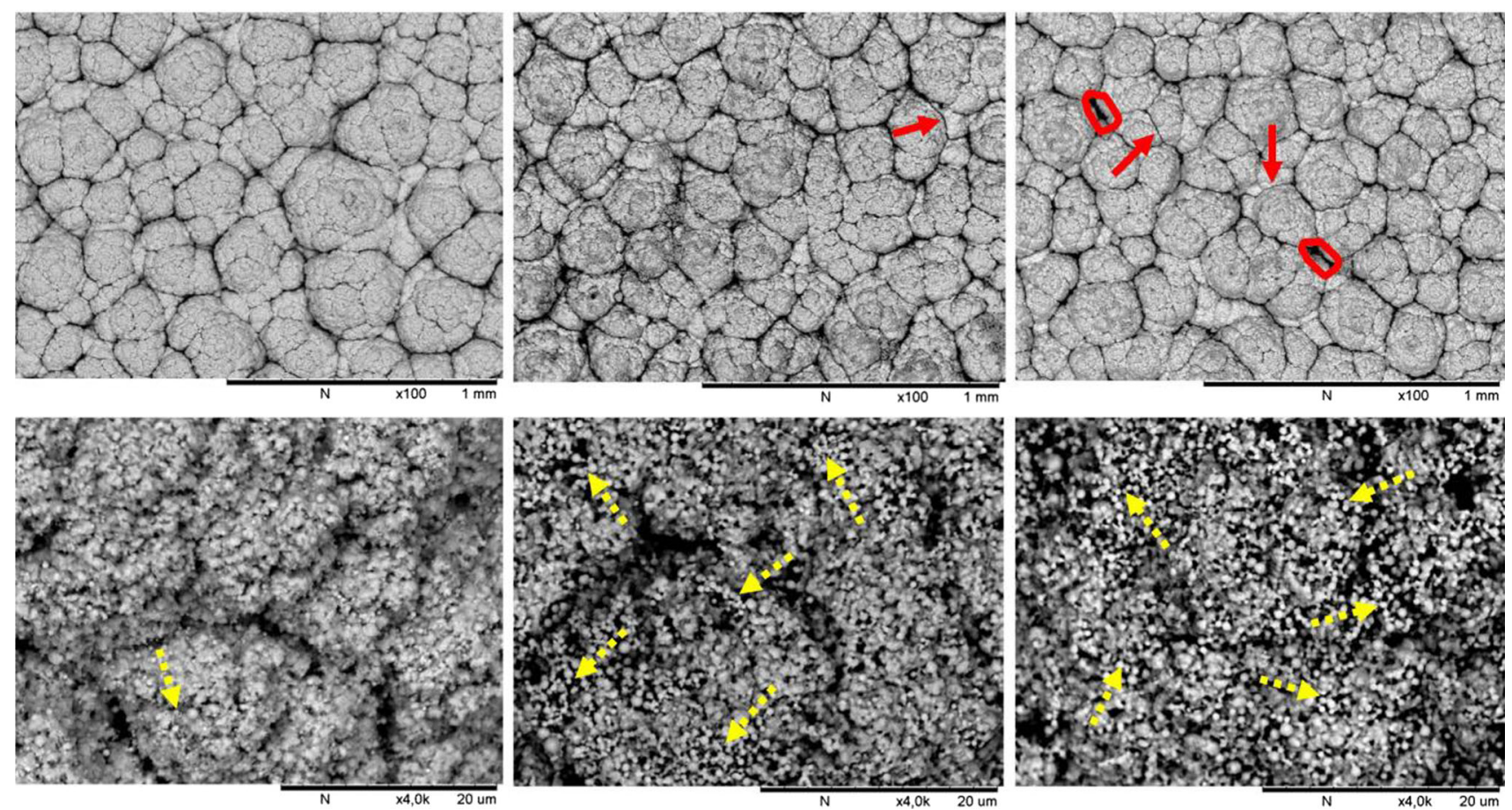

Fig. 11 SEM micrographs showing the top view of coating R1 in assprayed condition (left), after 200 cycles (middle) and 400 cycles (right) of cyclic heat treatment at $1100{ }^{\circ} \mathrm{C}$. The top row shows the

images at low magnification, while the bottom row shows the images at high magnification
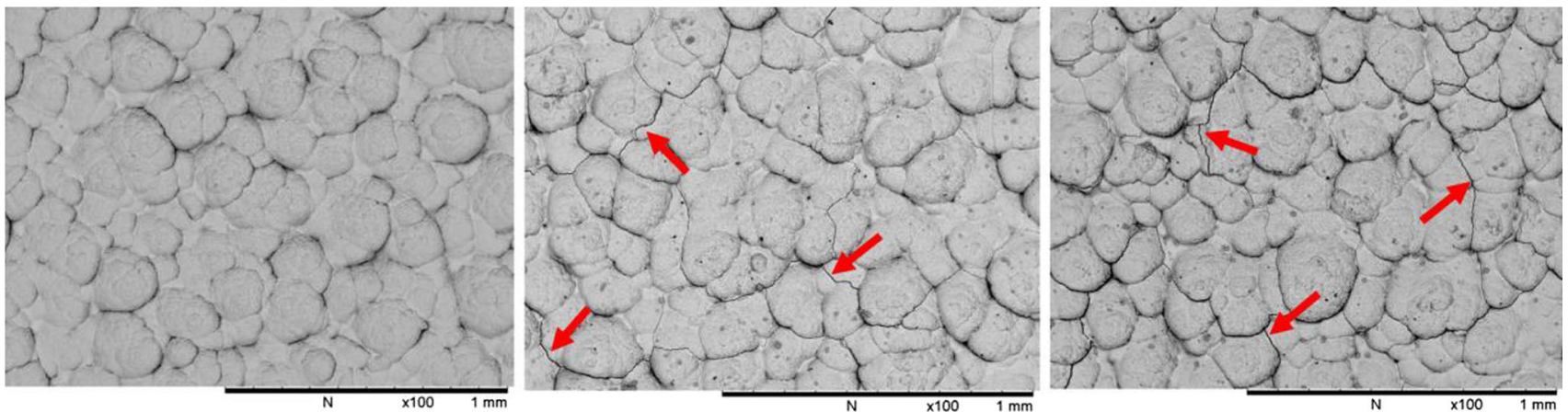
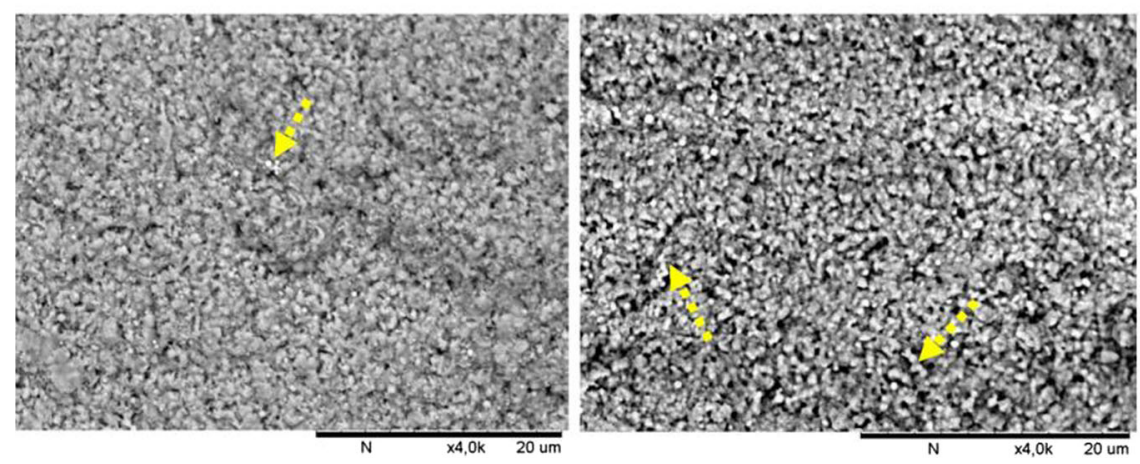

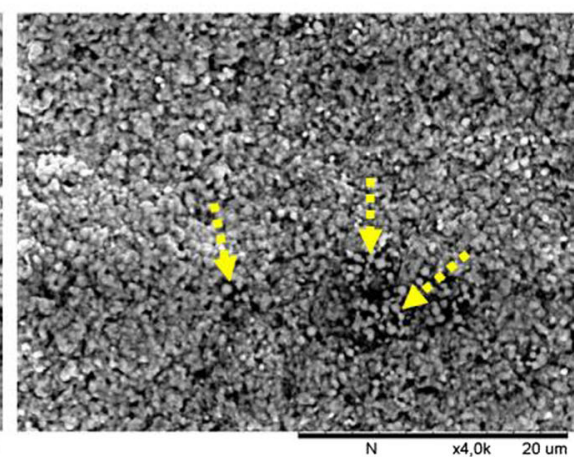

Fig. 12 SEM micrographs showing the top view of coating R6 in assprayed condition (left), after 200 cycles (middle) and 400 cycles (right) of cyclic heat treatment at $1100{ }^{\circ} \mathrm{C}$. The top row shows the images at low magnification, while the bottom row shows the images at high magnification 


\section{Conclusion}

In this work, seven types of SPS TBCs were investigated. The effect of topcoat spray parameters on the thermal conductivity and lifetime of TBCs was studied. The microstructure of as-sprayed samples shows that SPS is capable of producing variety of microstructures which can be categorized in feathery type, densely packed columnar type and porous columnar type.

The thermal conductivity results show that porous columnar-type TBCs exhibited lowest thermal conductivity, while the densely packed columnar-type coatings had the highest thermal conductivity. The bilayer topcoat of R7 showed a high thermal conductivity value between the porous and dense coatings as expected.

All coatings produced in this study showed high TCF lifetime. The failure mode in TCF testing was due to cracking within the TGO layer at the topcoat-bond coat interface in all the coatings. The coating R2 having columnar microstructure showed slightly higher lifetime than other coatings which may be due to the better strain tolerance that could inhibit the stresses developed during thermal cycling. Bilayer topcoat of R7 did not improve the TCF lifetime as expected. The dense first layer did not seem to significantly influence the lifetime in TCF testing.

Significant changes in topcoat microstructure were seen due to sintering after thermal cyclic heat treatment, more evidently in porous topcoats. Shrinking of columns or widening of inter-columnar gaps was observed and fine spherical shaped particles were seen to be forming cluster by fusing together. The dense topcoats did not undergo drastic changes in their microstructure even after 400 cycles of heat treatment which may be attributed to low initial porosity and high sintering resistance.

Acknowledgments The authors would like to acknowledge the Knowledge Foundation for funding of this work. Thanks to Stefan Björklund for the help with spraying of samples.

Open Access This article is distributed under the terms of the Creative Commons Attribution 4.0 International License (http://crea tivecommons.org/licenses/by/4.0/), which permits unrestricted use, distribution, and reproduction in any medium, provided you give appropriate credit to the original author(s) and the source, provide a link to the Creative Commons license, and indicate if changes were made.

\section{References}

1. R.A. Miller, Thermal Barrier Coatings for Aircraft Engines: History and Directions, J. Therm. Spray Technol., 1997, 6(1), p 35-42

2. R. Vassen, A. Stuke, and D. Stöver, Recent Developments in the Field of Thermal Barrier Coatings, J. Therm. Spray Technol., 2009, 18(2), p 181-186
3. C.U. Hardwicke and Y.-C. Lau, Advances in Thermal Spray Coatings for Gas Turbines and Energy Generation: A Review, $J$. Therm. Spray Technol., 2013, 22(5), p 564-576

4. B. Bernard, A. Quet, L. Bianchi, A. Joulia, A. Malié, V. Schick, and B. Rémy, Thermal Insulation Properties of YSZ Coatings: Suspension Plasma Spraying (SPS) versus Electron Beam Physical Vapor Deposition (EB-PVD) and Atmospheric Plasma Spraying (APS), Surf. Coat. Technol., 2017, 318, p 122-128

5. N. Markocsan, M. Gupta, S. Joshi, P. Nylén, X.H. Li, and J. Wigren, Liquid Feedstock Plasma Spraying: An Emerging Process for Advanced Thermal Barrier Coatings, J. Therm. Spray Technol., 2017, 26(6), p 1104-1114

6. N. Curry, K. VanEvery, T. Snyder, and N. Markocsan, Thermal Conductivity Analysis and Lifetime Testing of Suspension Plasma-Sprayed Thermal Barrier Coatings, Coatings., 2014, 4(3), p 630-650

7. A. Ganvir, N. Curry, N. Markocsan, P. Nylén, and F.L. Toma, Comparative Study of Suspension Plasma Sprayed and Suspension High Velocity Oxy-Fuel Sprayed YSZ Thermal Barrier Coatings, Surf. Coat. Technol., 2015, 268, p 70-76

8. A. Ganvir, N. Curry, N. Markocsan, P. Nylén, S. Joshi, M. Vilemova, and Z. Pala, Influence of Microstructure on Thermal Properties of Axial Suspension Plasma-Sprayed YSZ Thermal Barrier Coatings, J. Therm. Spray Technol., 2016, 25(1-2), p 202212

9. L. Pawlowski, Suspension and Solution Thermal Spray Coatings, Surf. Coat. Technol., 2009, 203(19), p 2807-2829

10. K. VanEvery, M.J.M. Krane, R.W. Trice, H. Wang, W. Porter, M. Besser, D. Sordelet, J. Ilavsky, and J. Almer, Column Formation in Suspension Plasma-Sprayed Coatings and Resultant Thermal Properties, J. Therm. Spray Technol., 2011, 20(4), p 817-828

11. R. Vaßen, H. Kaßner, G. Mauer, and D. Stöver, Suspension Plasma Spraying: Process Characteristics and Applications, $J$. Therm. Spray Technol., 2010, 19(1-2), p 219-225

12. N. Curry, Z. Tang, N. Markocsan, and P. Nylén, Influence of Bond Coat Surface Roughness on the Structure of Axial Suspension Plasma Spray Thermal Barrier Coatings-Thermal and Lifetime Performance, Surf. Coat. Technol., 2015, 268, p 15-23

13. A. Ganvir, N. Curry, S. Björklund, N. Markocsan, and P. Nylén, Characterization of Microstructure and Thermal Properties of YSZ Coatings Obtained by Axial Suspension Plasma Spraying (ASPS), J. Therm. Spray Technol., 2015, 24(7), p 1195-1204

14. A.G. Evans, D.R. Mumm, J.W. Hutchinson, G.H. Meier, and F.S. Pettit, Mechanisms Controlling the Durability of Thermal Barrier Coatings, Prog. Mater Sci., 2001, 46(5), p 505-553

15. D. Zhou, O. Guillon, and R. Vaßen, Development of YSZ Thermal Barrier Coatings Using Axial Suspension Plasma Spraying, Coatings., 2017, 7(8), p 120

16. R. Vaßen, F. Traeger, and D. Stöver, Correlation Between Spraying Conditions and Microcrack Density and Their Influence on Thermal Cycling Life of Thermal Barrier Coatings, J. Therm. Spray Technol., 2004, 13(3), p 396-404

17. M. Gupta, K. Skogsberg, and P. Nylén, Influence of TopcoatBondcoat Interface Roughness on Stresses and Lifetime in Thermal Barrier Coatings, J. Therm. Spray Technol., 2014, 23(12), p 170-181

18. K.W. Schlichting, N.P. Padture, E.H. Jordan, and M. Gell, Failure Modes in Plasma Sprayed Thermal Barrier Coatings, Mater. Sci. Eng., A, 2003, 342(1-2), p 120-130

19. O. Trunova, T. Beck, R. Herzog, R.W. Steinbrech, and L. Singheiser, Damage Mechanisms and Lifetime Behavior of Plasma Sprayed Thermal Barrier Coating Systems for Gas TurbinesPart I: Experiments, Surf. Coat. Technol., 2008, 202(20), p 50275032

20. A. Ganvir, S. Joshi, N. Markocsan, and R. Vaßen, Tailoring Columnar Microstructure of Axial Suspension Plasma Sprayed 
TBCs for Superior Thermal Shock Performance, Mater. Des., 2018, 144, p 192-208

21. B. Bernard, A. Quet, L. Bianchi, V. Schick, A. Joulia, A. Malié, and B. Rémy, Effect of Suspension Plasma-Sprayed YSZ Columnar Microstructure and Bond Coat Surface Preparation on Thermal Barrier Coating Properties, J. Therm. Spray Technol., 2017, 26(6), p 1025-1037

22. B. Siebert, C. Funke, R. Vaßen, and D. Stöver, Changes in Porosity and Young's Modulus Due to Sintering of Plasma Sprayed Thermal Barrier Coatings, J. Mater. Process. Technol., 1999, 92, p 217-223

23. F. Cernuschi, L. Lorenzoni, S. Ahmaniemi, P. Vuoristo, and T. Mäntylä, Studies of the Sintering Kinetics of Thick Thermal Barrier Coatings by Thermal Diffusivity Measurements, J. Eur. Ceram. Soc., 2005, 25, p 393-400

24. M. Ahrens, S. Lampenscherf, R. Vaßen, and D. Stöver, Sintering and Creep Processes in Plasma-Sprayed Thermal Barrier Coatings, J. Therm. Spray Technol., 2004, 13(3), p 432-442

25. M. Gupta, N. Markocsan, X.H. Li, and R.L. Peng, Improving the Lifetime of Suspension Plasma Sprayed Thermal Barrier Coatings, Surf. Coat. Technol., 2017, 332, p 550-559

26. A. Ganvir, N. Markocsan, and S. Joshi, Influence of Isothermal Heat Treatment on Porosity and Crystallite Size in Axial Suspension Plasma Sprayed Thermal Barrier Coatings for Gas Turbine Applications, Coatings., 2017, 7(1), p 4

27. M.R. Loghman-Estarki, R.S. Razavi, and H. Jamali, Thermal Stability and Sintering Behavior of Plasma Sprayed Nanostructured 7YSZ, 15YSZ and 5.5SYSZ Coatings at Elevated Temperatures, Ceram. Int., 2016, 42(13), p 14374-14383

28. R.S. Lima and B.R. Marple, Nanostructured YSZ Thermal Barrier Coatings Engineered to Counteract Sintering Effects, Mater. Sci. Eng., A, 2008, 485(1-2), p 182-193
29. V. Viswanathan, G. Dwivedi, and S. Sampath, Engineered Multilayer Thermal Barrier Coatings for Enhanced Durability and Functional Performance, J. Am. Ceram. Soc., 2014, 97(3), p 2770-2778

30. ImageJ Software. Image Processing and Analysis in Java. http:// imagej.nih.gov/ij/, Accessed: 17 Nov 2014

31. S. Mahade, N. Curry, S. Björklund, N. Markocsan, and P. Nylén, Thermal Conductivity and Thermal Cyclic Fatigue of Multilayered $\mathrm{Gd}_{2} \mathrm{Zr}_{2} \mathrm{O}_{7} / \mathrm{YSZ}$ Thermal Barrier Coatings Processed by Suspension Plasma Spray, Surf. Coat. Technol., 2015, 283, p 329336

32. F. Cernuschi, P. Bison, and J.G. Sun, Thermal Diffusivity of TBC: Results of A Small Round Robin Test and Considerations about the Effect of the Surface Preparation and the Measuring Approach, Surf. Coat. Technol., 2014, 258, p 284-292

33. H. Guo, S. Kuroda, and H. Murakami, Microstructures and Properties of Plasma-Sprayed Segmented Thermal Barrier Coatings, J. Am. Ceram. Soc., 2006, 89(4), p 1432-1439

34. P. Carpio, Q. Blochet, B. Pateyron, L. Pawlowski, M.D. Salvador, A. Borrell, and E. Sánchez, Correlation of Thermal Conductivity of Suspension Plasma Sprayed Yttria Stabilized Zirconia Coatings with Some Microstructural Effects, Mater. Lett., 2013, 107, p 370-373

35. N. Curry, K. VanEvery, T. Snyder, J. Susnjar, and S. Björklund, Performance Testing of Suspension Plasma Sprayed Thermal Barrier Coatings Produced with Varied Suspension Parameters, Coatings., 2015, 5(3), p 338-356

36. A. Ganvir, S. Govindarajan, N. Curry, and N. Markocsan, Characterization of Thermal Barrier Coatings Produced by Various Thermal Spray Techniques Using Solid Powder, Suspension, and Solution Precursor Feedstock Material, Int. J. Appl. Ceram. Technol., 2016, 13(2), p 324-332 